Making connections and building resilience: Developing workshops with undergraduates

\author{
Julia Anthoney \\ Rachel Stead \\ Katie Turney \\ University of Surrey, UK
}

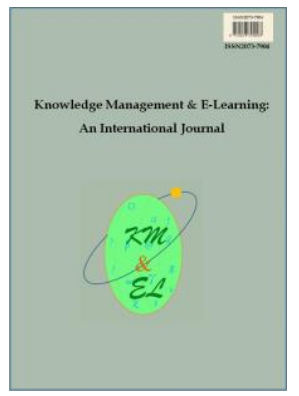

Knowledge Management \& E-Learning: An International Journal (KM\&EL) ISSN 2073-7904

Recommended citation:

Anthoney, J., Stead, R., \& Turney, K. (2017). Making connections and building resilience: Developing workshops with undergraduates. Knowledge Management \& E-Learning, 9(3), 404-418. 


\title{
Making connections and building resilience: Developing workshops with undergraduates
}

\author{
Julia Anthoney* \\ University of Surrey, UK \\ E-mail: j.anthoney@surrey.ac.uk
}

\section{Rachel Stead}

University of Surrey, UK

E-mail: r.stead@surrey.ac.uk

\section{Katie Turney \\ University of Surrey, UK \\ E-mail: kt00214@surrey.ac.uk}

*Corresponding author

\begin{abstract}
While defining resilience is recognised as complex with recent research highlighting the disparity of interpretations, there is however, a common appreciation of the wide range of contributory factors impacting on students' resilience within the Higher Education sector. These can include but are not limited to, an increasingly competitive environment for graduate jobs, increased financial pressure from student tuition fees, alongside the more traditional concerns of moving away from home and transitioning towards greater independence. Building on previous research at the University of Surrey with high achieving students, this paper outlines the development and delivery of a student focused workshop designed to enable the participants to build their understanding of resilience using different but complementary pedagogic approaches: LEGO ${ }^{\circledR}$ SERIOUS PLAY® and Concept Mapping. The case study included within this paper demonstrates one student's reflection of the workshop and previous experiences which have contributed to their own resilience. What has become apparent at the University of Surrey, and more broadly within the UK Higher Education sector, is that universities have a vital role to play in fostering positive mindsets amongst students and developing strong and resilient independent learners.
\end{abstract}

Keywords: Transitioning; Mindsets; Learning development; Wellbeing; LEGO® SERIOUS PLAY®

Biographical notes: Julia Anthoney is a Student Learning Adviser working in Learning Development at the University of Surrey. Julia's research interests include the differentiated needs of high-achieving students with a focus on personal and professional development.

Rachel Stead is a Student Learning Adviser working in Learning Development at the University of Surrey. Rachel's research interests lie in Constructionist learning in particular LEGO® SERIOUS PLAY® and Playdoh modelling to aid reflection and deepen understanding. 
Katie Turney is a 2nd year Veterinary Medicine student at University of Surrey, UK.

\section{Introduction}

\subsection{Rationale and underpinning literature}

There is much talk in the higher education (HE) sector about resilience but few agreed definitions other than an understanding of its complexity (see Jackson, Firtko, \& Edenborough, 2007). Whilst some studies frame resilience in terms of personality traits and characteristics, some see it along a continuum with vulnerability and resilience as opposite extremes. Others still focus on personal values and belief systems, or see resilience as a set of skills and strategies (Jackson, Firtko, \& Edenborough, 2007). Despite a lack of consensus within the research community with regards to one clear definition of resilience, there is a growing body of research instead highlighting common internal and external factors which play an important role in building personal resilience.

Intrinsic motivators, such as a strong sense of self and purpose (Winstone, 2017) and high levels of self-efficacy (Schwarzer \& Warner, 2012) have a significant role to play in fostering resilience. Holdsworth, Turner, and Scott-Young (2017) discuss the importance of positive protective factors which inform resilience and they categorise these into internal and external. According to Johnson (2008), optimism, self-efficacy and psychological well-being are key internal factors whilst a caring supportive network, the belief of others in one's abilities and a sense of belonging and contributing to an academic community in a meaningful way (see Dickinson, 2012) are significant external factors which help to foster students' resilience.

Our own analysis of working with students on the subject of resilience aligns more closely with that of Jackson, Firtko, and Edenborough (2007, p. 3) who define resilience as an active process which refers to an individual's ability to "adjust to adversity, maintain equilibrium, retain some sense of control over their environment, and continue to move on in a positive manner". This is further supported by Holdsworth, Turner, and Scott-Young $(2017$, p. 2) whose interpretation of resilience is rather less definitive but emerges as a dynamic capability involving, "ways of thinking and acting that can be learnt and developed" and it is this which is key to our programme of personal, academic and professional development and will be explored further in this paper.

Numerous challenges present themselves to students upon entering HE, such as managing finances, transitioning from school or college to university, peer pressure and competition, one or more of which may impact on a student's ability to be resilient. Historically students have had to manage their own finances but since The Browne Report (2010) and the subsequent raising of university student tuition fees in the UK to $£ 9000$ per annum, there are the additional pressures of rising student debt and the implications on academic performance and expectations that may result. Transitioning into HE presents its own unique set of challenges, as recognised by The Guardian (2015) who refer to contributing factors such as living independently, lack of structure, independent learning, and being surrounded by more able and highly competitive peers. This is also supported by Kinchin and Winstone (2017) who argue that students' academic expectations are challenged when they begin their HE courses and are no 
longer achieving the high grades to which they may have been accustomed. Likewise, Caruana, Clegg, Ploner, Stevenson, and Wood (2011) recognise the challenges faced by students entering university; not only are they embarking on a transition to HE, most are also transitioning to adulthood. Transitioning can also refer to students acclimatising between university and work placements and vice versa. For high achieving students, replicating academic success in their work placements may prove problematic. According to ASET (2017), students may have become accustomed to instant feedback on their academic assignments, and may, therefore, have the same expectations from their employers and the work environment, which can have a direct impact on their confidence. Added to this, there is the additional pressure of future employability and intense competition for the highest paid positions with the best remuneration packages, in an environment where $22 \%$ of students in UK Universities graduate with a $1^{\text {st }}$ Class honours degree (HESA, 2016).

The impact of these challenges has been highlighted in The Guardian (2016), who report a rise of approximately $50 \%$ in demand for wellbeing and mental health support services in UK universities over a 5-year period between 2011 and 2016. This is further supported by more up to date figures reported by The Guardian (2017), which claim a $210 \%$ increase (since 2009-10) in students reported to have left university as a result of mental health issues. Ruth Caleb, chair of Universities UK's Mental Wellbeing in Higher Education working group, points to a huge rise in demand for mental health support services across the UK HE sector, with counselling services facing an annual increase in demand of approximately 10\% (Coughlan, 2015).

At the University of Surrey, the situation is reported to be approaching a 30\% rise in students seeking support from wellbeing services over the period April 2016 to April 2017. This is corroborated by the university's Employability and Careers Centre (ECC) who report an upward trend, over the 5 years to 2017, in mental health issues experienced whilst on Professional Training Year placements with the subsequent impact of increased dropout rates which reflects the broader UK trend, highlighted above. However, this challenge continues beyond tertiary education with a growing requirement for resilient employees in the work place. According to Ransley (2017), resilience is increasingly being sought as a graduate attribute by industry recruiters across the UK which may be due to changes in the job market during the ongoing period of austerity and expectations that individuals will no longer stay with one company on a long-term basis (Robertson \& Cooper, 2013).

If we accept then that resilience is indeed a dynamic capability involving behaviours and ways of thinking that it is possible to learn and nurture and we couple this with feedback year on year from STARS (Surrey's Top Achievers Recognised and Supported) students at the University of Surrey which demonstrates recognition of the importance of engaging with and learning from failure, this therefore presents us with a key opportunity: as a university we have a pivotal role to play in helping our students to foster lifelong resilient mindsets . It is encouraging to find that our current understanding of our role is advocated in new research conducted by Turner, Holdsworth, and ScottYoung (2017) and McIntosh and Shaw (2017).

\subsection{Background and context}

The authors of this paper are members of a team of Learning Development (LD) professionals, working together with students to help them achieve their full potential, personally, academically, and professionally at the University of Surrey. Part of our remit 
is to support the differentiated needs of our high achieving students, known as STARS, initiated in 2011/12.

Year on year, a heuristic exercise to establish STARS students' self-identified needs consistently identify perfectionism as one of the top areas of concern. However, according to Dickinson and Dickinson (2014, p. 12), "Restructuring perfectionism within the discourse of academic resilience can lead to modifications in behaviour that contribute positively to the overall student experience". In so doing, they reframe student perception of perfectionism from one which is problematic and potentially injurious to wellbeing to one which is manageable and potentially positive for the student.

This has led to careful consideration of ways in which we could engage students in activities that would better facilitate their own understanding of contributing factors to resilience.

\section{Method}

\subsection{How the workshop was developed}

A pilot session was conducted with six members of staff from the Department of Higher Education (DHE), using two different but complementary activities: LEGO® SERIOUS PLAY ${ }^{\circledR}$ (LSP) modelling and building concept maps of resilience. LSP is a creative, hands-on, concrete thinking methodology, adhering to Papert's Constructionist theory of learning (see Ackermann, 2001), whereby participants aim to make concepts more tangible and visible for discussion, reflection and meaning making. Concept mapping (Novak, 2010) is a tool which has long been used for the delivery of content to support learning, yet it is increasingly being used to facilitate deeper understanding of the values which support teaching and learning. The process of concept mapping enables people to not only gain better understandings of phenomena, but also to attach personal significance to these through reflection and self-discovery (Kinchin, 2017). Building on the feedback received following this pilot, a student-focused workshop was developed.

The current workshop was held in March 2017 with undergraduates from across the disciplines at the University of Surrey. Delivered and facilitated by members of staff from the LD Team, DHE and The Employability and Careers Centre (ECC), the session consisted of both informative talks and hands-on activities and was largely divided into 3 main themes: the students' current individual understandings of resilience; important factors which may help or hinder resilience; and shared development of strategies to foster resilient mindsets.

\subsection{Building resilience through LEGO® SERIOUS PLAY®}

The principal activity in this first section asked the students to create individual models of their personal understandings of resilience, addressing the question, "What does Resilience mean to you?" using a LSP approach. Advocates of LSP argue that building metaphorical models to represent concepts prompts individuals to view their ideas from different angles, to explore connections between ideas and to open up dialogue with others leading to deeper meaning making and reflection (e.g. Gauntlett, 2007; James, 2013; James \& Brookfield, 2014; Peabody \& Noyes, 2017). Amongst Gauntlett's (2007) key findings were that the use of representational objects and metaphor allows simultaneous presentation of the 'co-existence and inter-relatedness' of separate ideas or 
concepts in a way that it is very difficult to do using language which requires more of a rigid structure and hierarchical approach. Whilst Piaget regarded this 'concrete thinking' as inferior to abstract thought and something which children outgrow, Papert instead sees concrete and abstract thinking as complementary and a way in which we can embrace, what Sotto (2007) terms, a more holistic approach to thinking.

In the workshop, having built their models, the students then shared and discussed them with a peer in order to extrapolate some of the key themes, which were then recorded on post it notes and placed around the models. Due to the sensitive nature of personal information, students were reassured that they were not obliged to share anything which they considered too private, which is supported by LSP best practice (see Gauntlett, 2007). The group as a whole was invited to view all the other models in order to attempt to identify some of the most common themes emerging.

\subsection{Factors which may help or hinder resilience}

The first discussion was centred around the duality of the fixed mindset vs. the growth mindset (Dweck, 2015). This essentially espouses the belief that intelligence is either a basic factor which cannot be changed or that it can be substantially changed and developed. This duality of mindsets closely aligns with the idea of a Locus of Control (Rotter, 1954) which refers to the degree to which a person believes they have control over the outcome of events in their lives. An individual with an external locus of control believes that external forces are responsible for the outcome whilst those with internal loci believe that they have control over their own lives.

Rationale for introducing this idea and gauging the students' stance on mindsets was to open up discussion on the possibilities of adopting a more resilient approach to their personal, academic and professional activities. According to Dweck (2015), those with a growth mindset are more likely to view failure as an important aspect of their learning journey and one which helps them to achieve success in the longer term. Those with a fixed mindset tend to see failure as a verdict on themselves, personally, rather than as a verdict on a one-off situation or event.

Following this discussion, we looked at the science behind resilience: the physiological effects of our lifestyle choices and of stress, in order to help the students to understand that they can have more control (see Jackson, Firtko, \& Edenborough, 2007) over their stress levels, negative emotions and lack of resilience, which may in turn impact more positively on their ability to perform and succeed.

The logic behind focussing on the psychological aspect of mindsets is based upon the authors' belief that it is an underpinning tenet of developing resilience (see Dweck, 2014; 2015). Evidence for the importance of raising awareness of physiological factors which can cause stress and, therefore, impact upon resilience comes from the scientific literature on cortisol (see Cotman \& Berchtold, 2002; Vgontzas et al., 2003).

\subsection{Shared development of strategies to foster resilient mindsets}

Having gauged student perceptions and discussed factors impacting resilience, the third and main section of the workshop focussed on a concept mapping approach to developing strategies for building resilience. The students were divided into groups of four and a brief introductory discussion was led by the Learning Development team about concept mapping as a useful tool for generating greater understanding. According to Kinchin (2017, p. 3), concept maps are not merely a means to summarise information 
diagrammatically; they should be viewed instead as tools which can facilitate exploration of the relationships presented therein, and ultimately prompt dialogue. Kinchin (2016) stresses that it is the recognition of the nature of the relationships between ideas that can facilitate the development of strategies to address concerns.

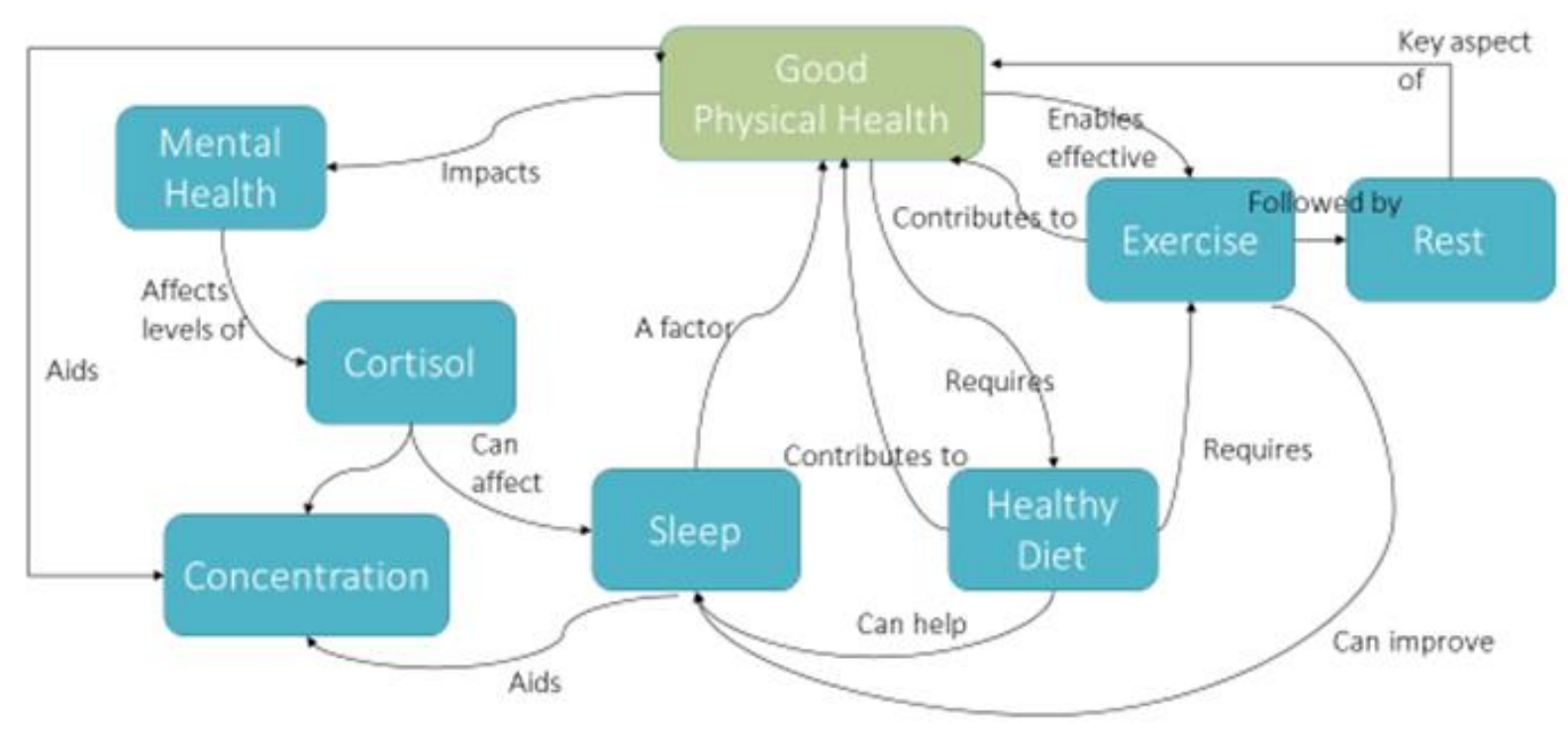

Fig. 1. Example concept map with scenario

An example concept map with a scenario (see Fig. 1) was shown to provide guidance as to the expected outcomes of the activity as well as provide a backdrop for the students' thinking. They were tasked with selecting from a range of concepts linked to resilience, which included: mental health, physical health, support network and happiness, and were provided with a list of suggestions of useful connecting words and phrases in order to create their group concept map (see Tables 1,2).

Table 1

Range of concepts associated with resilience (drawn from previous resilience workshops at University of Surrey) for concept mapping exercise

\begin{tabular}{ll}
\hline Support network & Perfectionism \\
Coping strategies/Dealing with adversity & Flexibility / Adaptability \\
Perspective & Success \\
Value & Organisation \\
Motivation (Intrinsic and extrinsic) & Development (Personal and academic) \\
Perseverance & Happiness \\
Mental and emotional health & Academic health \\
\hline
\end{tabular}

A final year student received a significantly lower than expected grade in their exams. The grade now means that they have to achieve a very high grade in their 
dissertation in order to achieve a first. They also have 2 more assignments due in the next 2 weeks and they have a couple of job interviews lined up -feeling really down, disappointed, suddenly overwhelmed by the amount of work needed -what can they do to develop their resilience?

\section{Table 2}

Example connectors/links (Garcia-Dia, DiNapoli, Garcia-Ona, Jakubowski, \& O'flaherty,2013)

\begin{tabular}{lll}
\hline Including & Characterised by & During and after \\
Invokes & Impacts & Internal \\
External & Apparent & Overcoming \\
Leads to & May be seen as & Requires \\
\hline
\end{tabular}

During the activity, facilitators circulated to provide guidance and to question, challenge and prompt the students to encourage reflection on both their thinking and their choices during the construction of their maps. Once the small groups had completed their maps, the whole group reconvened for feedback in order to demonstrate the many and varied aspects involved in resilience and the complex relationships between them.

\section{Results and discussion}

Students' initial feedback was sought via 2 questions which were asked upon arrival. This was synthesized into two themes (see Table 3).

Table 3

Students' initial feedback (synthesized into themes) questions asked upon arrival

\begin{tabular}{cc}
\hline What attracted you to the event? & What do you hope to get out of the event? \\
\hline $\begin{array}{c}\text { A desire to engage with the STARS programme } \\
\text { Previous positive engagement with STARS }\end{array}$ & $\begin{array}{c}\text { Confidence building } \\
\text { Adaptability } \\
\text { A desire to find out more about resilience, what it } \\
\text { means, why it's important } \\
\begin{array}{c}\text { Recognition of resilience being an employability } \\
\text { skill they need to demonstrate }\end{array} \\
\begin{array}{c}\text { Recognition that resilience is a skill they need to } \\
\text { develop in order to manage stress }\end{array} \\
\begin{array}{c}\text { Tools and techniques to help to cope with } \\
\text { significant change }\end{array} \\
\text { Tips for engaging with failure }\end{array}$ \\
\end{tabular}

\subsection{Opening group activity}

This produced some interesting but unsurprising results; all but one of the students described themselves as perfectionists who would only be happy graduating with a first. This is supported by Dickinson and Dickinson $(2014$, p. 1) who found that "one of the most frequent self-reported challenges within this high-achieving group is perfectionism". Other interesting results revealed the majority of students believed that their determination was more important than their talent in helping them succeed. The 
only student who believed her talent was more important than her determination asserted that in her opinion a person's intelligence is formulated by the age of eleven with little or no subsequent determination impacting on their ability to succeed. This links in with Dweck's $(2014 ; 2015)$ fixed mindset belief but is also based upon the idea that intelligence can be measured through simple IQ tests alone. The authors' preferred understanding of intelligence is one which is more aligned with Gardner's theory of Multiple Intelligences (see Gardner, 1993) which encompasses a broader view of what constitutes intelligence to include not only the verbal / linguistic and mathematical / logical domains traditionally measured but also abilities such as inter and intrapersonal skills, cultural competencies, visual-spatial awareness and musicality.

\subsection{Building resilience $-L E G O \circledR$ models}

Fig. 2 below shows a selection of students' LSP models in response to the question: What does resilience mean to you? Themes, in students' own words, are presented below each image.
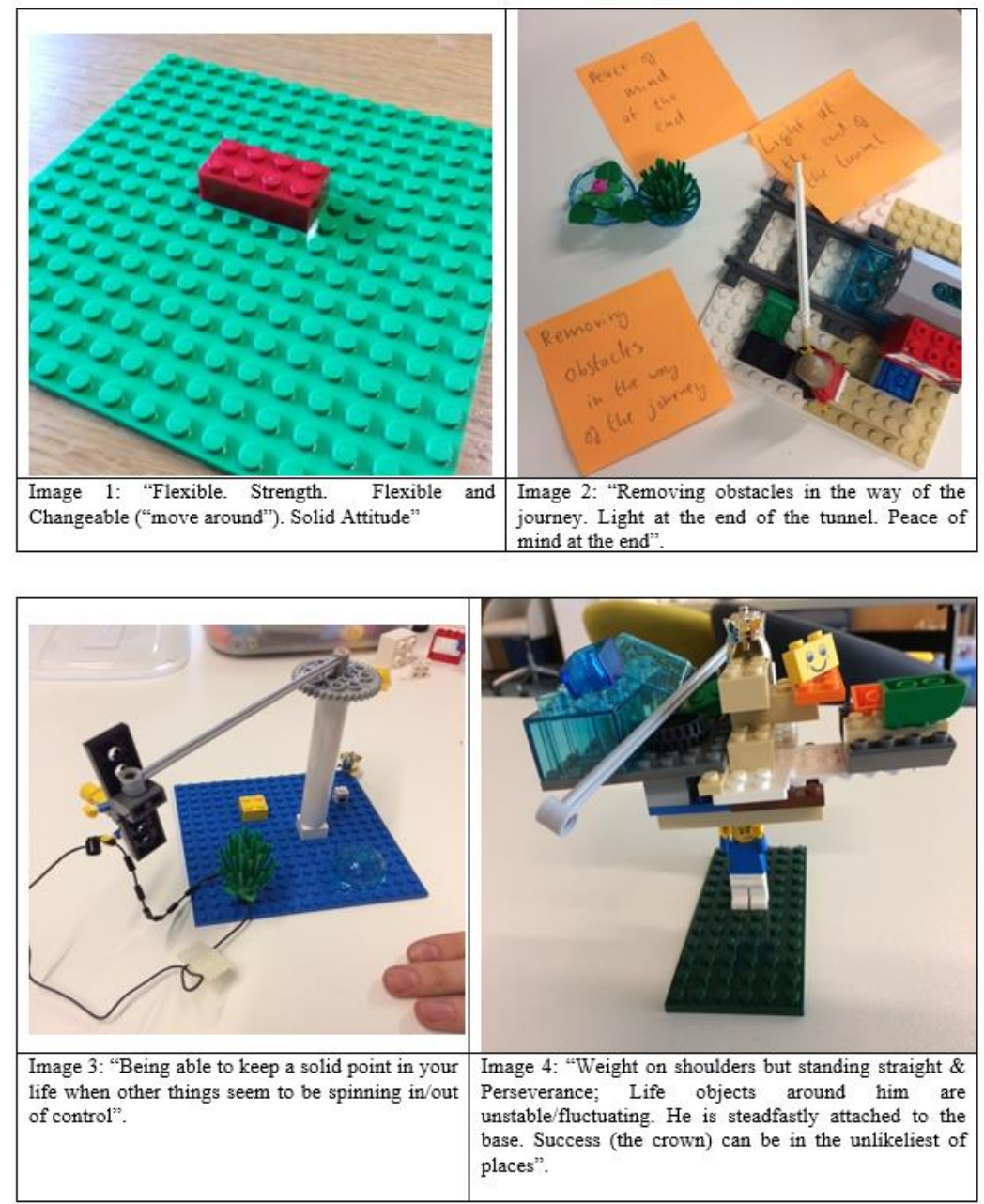

Fig. 2. LEGO® SERIOUS PLAY® models of resilience 
As a whole, the students' self-identified themes appear to fall into the following four categories: strength and stability, awareness of the external influences and obstacles, perseverance and flexibility, and end goals. These themes align closely with Jackson, Firtko and Edenborough's (2007, p. 3) definition of resilience (see above) which identifies the need to adjust to adversity (flexibility), maintain equilibrium (strength and stability), retain some sense of control over their environment (awareness of external influences) and continue to move on in a positive manner (perseverance).

\subsection{Group concept maps of resilience}

Below are two examples of authentic student concept maps from the workshop. One shows students' use of pen and paper (see Fig. 3), whilst the other shows the students' use of post-it notes (see Fig. 4).

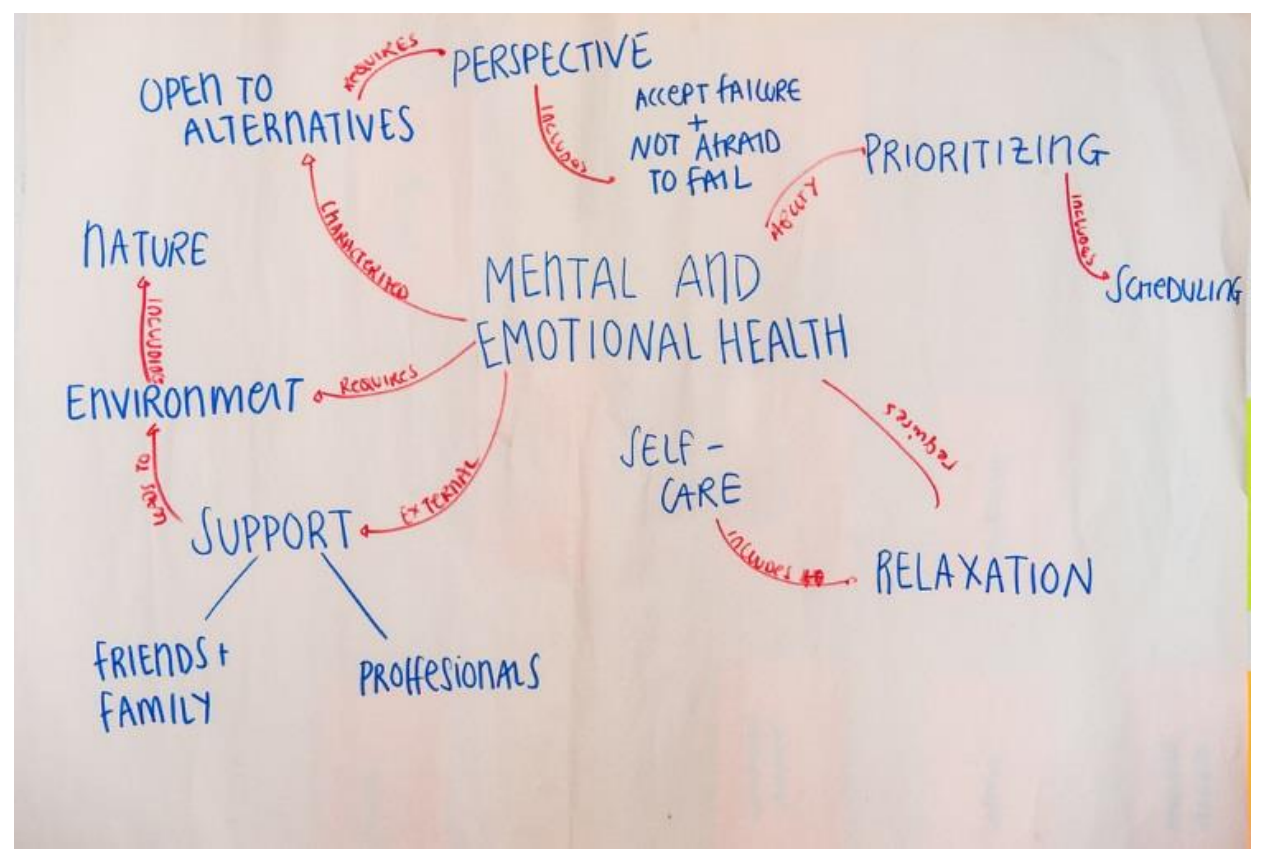

Fig. 3. Photo of original concept map for 'Mental and emotional health'

It was decided to include photos of the original maps rather than redrawn Cmaps. This was done not only to preserve the authenticity of the images but also to demonstrate the dynamic nature of the activity and the different ways in which it can be approached.

Feedback from the session demonstrated that there was perceived value in discussing aspects of resilience during the concept mapping activity and reflect upon these which is supported by Kinchin (2017, p. 3). However, it was also evident that there were disagreements and difficulties in arriving at one shared agreed map of resilience, as was the case during the pilot, to which we had responded by narrowing the task to mapping common factors associated with resilience rather than attempting to map the concept in its entirety. Resilience, as with many concepts, is likely to mean different things to different individuals and hence, this is also the rationale behind suggesting the students undertake the follow-up activities: creating their own personal maps and reflecting on both the session and their own resilience in a case study. 


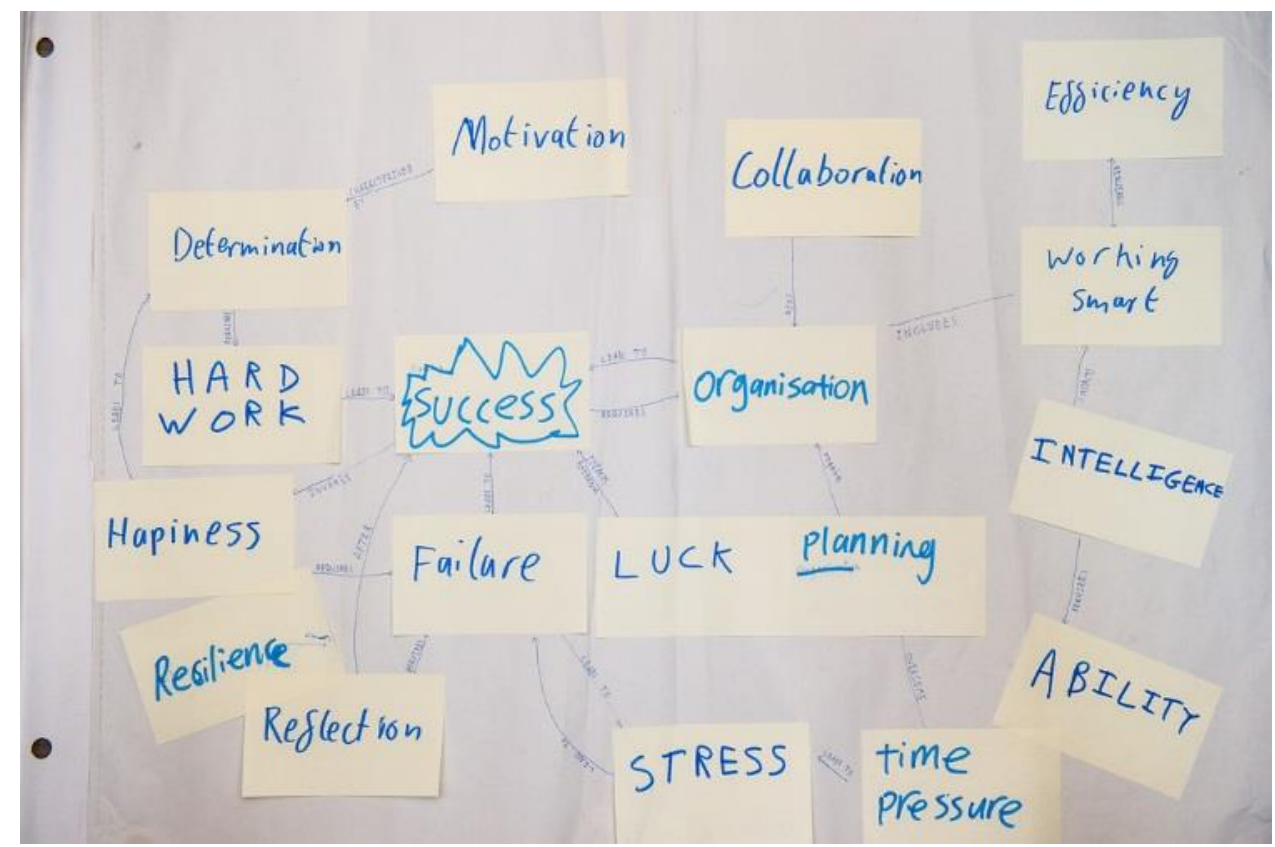

Fig. 4. Photo of original concept map for 'Success'

Concept mapping provides a natural progression from the LSP modelling: from identifying factors involved and the relationships between them and reflecting on these in LSP, to specifying the nature of those relationships in order to deepen understanding (see Kinchin, 2017). The students progressed from the creation of a visual representation of their tacit understanding of resilience towards a greater ability to articulate this meaningfully using language in order, ultimately, to begin to devise strategies to build resilience.

Apart from the obvious commonality between LSP and concept mapping, both being vehicles for dialogue and reflection, another key similarity between these activities which has since occurred to the authors is the opportunities that both provide for the externalisation of personal beliefs and sometimes private ideas for analysis and discussion and viewing relationships between these ideas from another perspective.

\section{Follow up activities and case study}

\subsection{Follow up activities}

Prior to the closure of the resilience event, students were asked to undertake a follow up exercise to reflect on both their experiences and the resilience workshop, and to consider submitting a case study to demonstrate their enhanced understanding of their own resilience. One of the students agreed to write up her case study in her own words for inclusion in this paper and to produce her own personal concept map, both of which can be found below. 


\subsection{Case study}

Case Study - Katie Turney $-2^{\text {nd }}$ Year Undergraduate Veterinary Medicine- University of Surrey

Since I can remember, all I have wanted to be is a vet. Applying to university was therefore a daunting task, not to mention the necessity for exceptional A-Level grades (I was studying five A-Levels). There was an additional entrance exam, the constant redrafting of my personal statement, the time dedicated to filling out every detail of my UCAS form, and talks put on at school to hear about the value of higher education. It made me so excited, and I felt confident. So, when I received four out of four rejections, without so much as an interview, I was significantly knocked back. It was an emotional time of self-doubt and a lack of motivation as I contemplated what I would do with a gap year, but I am pleased to say that I showed great resilience during that time. This piece aims to demonstrate some important aspects of that resilience, so that other students might benefit from those mentioned in the face of failure.

Following my rejections, I worked just as hard on my studies and started a parttime job, but I always made sure I had time to spend with friends, and that was the biggest aspect of what got me through; my support network is very important to me those friends helped me emotionally, and some incredible staff gave me solid academic advice and started highlighting the many possible pathways which could still lead me to my goal. The people around me continually reminded me to never give up, and I heeded that statement faithfully.

In addition to my support system, I also had other small successes, and it is important that these are still valued, rather than being overlooked in the situation. I had continued academic achievements, awards in my extracurricular activities, and new roles such as that of Deputy House Captain. These successes were very rewarding, and they made me happy. I believe that this combination of success and happiness fuelled my confidence and self-esteem, and that that allowed me to hold the perspective that I was not a failure. Not in the slightest. I had not got into university yet, not this time. But that wouldn't stop me from trying again until I was successful.

In my gap year, I learnt the other significant thing which maintained my resilience: self-awareness. Working full time for a restaurant chain made me realise that I had many other skills and qualities in addition to academics, such as communication, leadership, teamwork, problem-solving, and many other practical things important for a veterinarian. I underwent massive personal development in my job, and I consistently believe that the range of skills I learnt there set me apart on my university application and led to my acceptance.

And I was accepted. I now study at the University of Surrey - I'm on the road to achieving my dream, and the resilience I gained from my experience is invaluable to me now. The STARS Resilience Workshop gave me the opportunity to reflect on all of the above, and really put a name to those things which advanced my progress in spite of failure; it added some clarity, which has given way to pride. Because I didn't give up, and I made it. And I am happy; happy because of what I have created - since those rejections I have not only started vet school, but my relationships have also improved, I am more committed to self-care, and the life skills from my gap year have meant that I could safely find a house to live in with my amazing housemates, not to mention the funds I saved which have allowed me to live comfortably. Resilience and happiness are intertwined, and with both I have come this far. And I keep going. 

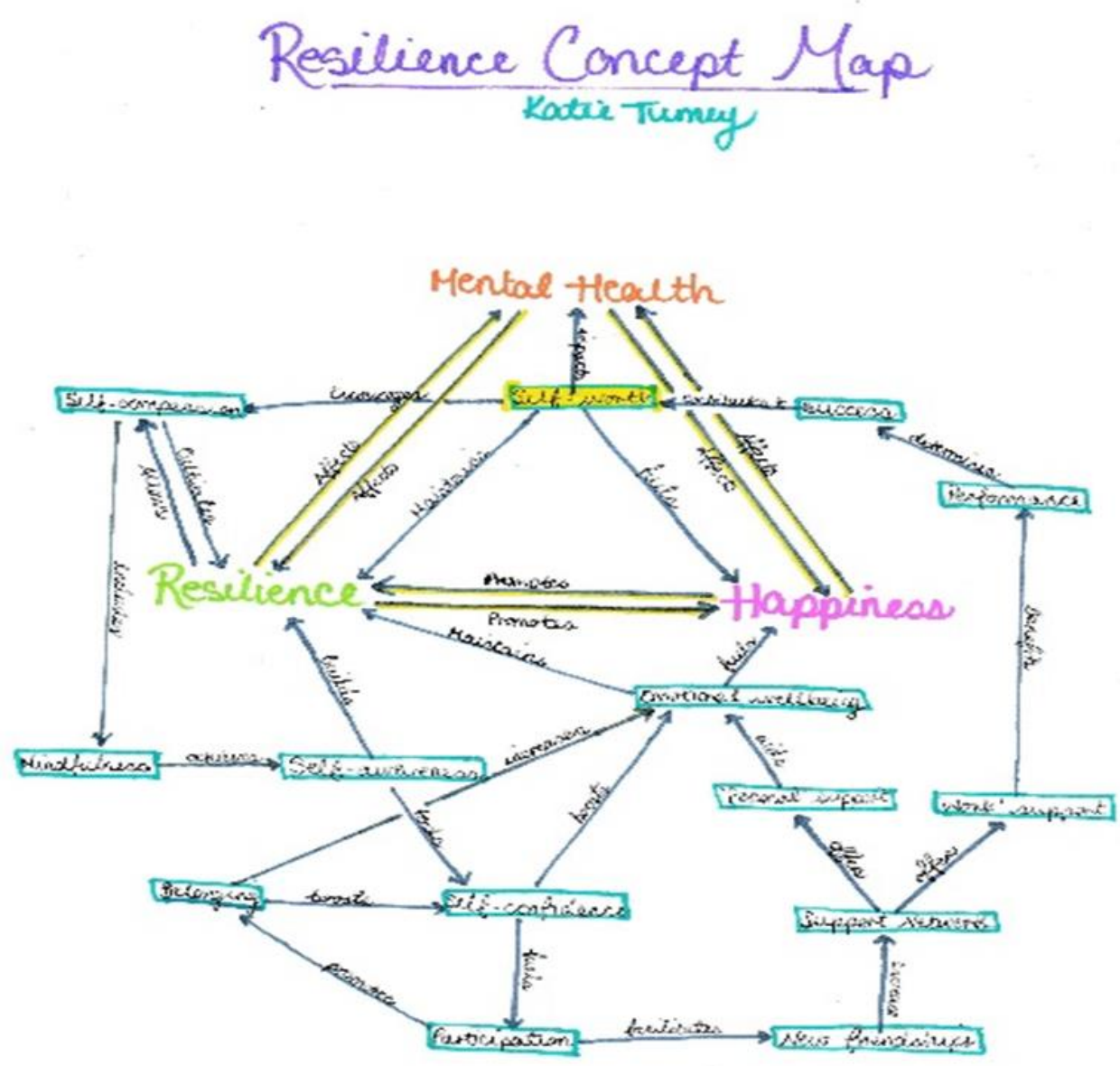

Fig. 5. Image of concept map created by Katie Turney

The links between Katie's narrative and her concept map (Fig. 5) can be found throughout; one such example can be found when Katie explains that: 'some incredible staff gave me solid academic advice and started highlighting the many possible pathways which could still lead me to my goal'. She represents this within her concept map whereby she recognises how 'work support' 'benefits' 'performance' which in turn 'determines' 'success'.

\section{Evaluation of the event}

The event was evaluated via questionnaires As well as generally gaining new perspectives on their own resilience and tips and strategies for managing their own stress, the students' specific and open comments in response to what they felt they had learnt from engaging in the activities naturally fell into three overarching themes: a new found appreciation of the complexity of resilience (e.g 'I have gained a new perspective on what resilience is about' and 'How complex resilience is'); the importance of adopting a growth mindset (e.g. 'I learnt about the fixed vs growth mindsets and how they impact your attitudes and behaviours') ; and the fundamental importance of reflection as a tool 
for aiding this type of mindset (e.g. 'I will take more of a step back and think about the many factors that may be involved in my situations and how I could be more resilient in them.), all of which are amply supported by the literature in this paper.

\section{Conclusion}

It was noted in both observational feedback from colleagues in DHE, and by one of the participants in their evaluation of the session that some more time towards the end to reflect upon the processes and then to have an opportunity to develop strategies to respond to issues raised within their groups would have been appreciated.

This could be addressed by increasing the total time available for the session, which was two hours long. Another option would be to offer it as a two different but connected sessions, the downsides being though that we may lose some students and therefore would not have the longitudinal data. The sample size, whilst small (12 students), provided us with a rich data set which not only concurred with the authors' previous experiences of working with STARS students but was also reflective of the vast body of literature on the complexities of resilience.

Observational feedback from colleagues working in faculty development suggests there may be merit in offering a similar resilience workshop to new students joining University of Surrey. This could perhaps be offered via our Learning Development open access workshop programme and follows the suggestions of Holdsworth, Turner, and Scott-Young (2017) who argue that we have a key role to play in helping students to develop their resilience. This is echoed by McIntosh and Shaw (2017, p. 5) who argue strongly that resilience encompasses many of the traditional values and the overall purpose of HE, which is, "to nurture strong independent learners and to support the development of rounded individuals that can contribute positively to society".

However, with the discussions around resilience not merely being limited to students in HE but also applied to all workplace environments, an interesting question which needs further exploration is whether or not the issues are essentially the same for academics working within HE.

Challenges academics are faced with, for example, pressures of increased accountability and a results-driven culture (see Kinchin \& Winstone, 2017) which leads to new processes and continuous restructures are not dissimilar to students' experiences of the pressures of increased debt, transitioning, higher expectations, and a similarly results-driven environment. According to Winstone (2017), resilience in academics promotes adaptive responses to an ever-changing environment and it is these adaptive responses which act as buffers to what Kinchin (2015) terms 'pedagogic frailty'.

One aspect of diminished resilience, as discussed by Kinchin and Winstone (2017) is external locus of control, which the authors see as inextricably linked to a fixed mindset perspective (Dweck, 2015). In order to promote and build resilience, it is the authors' recommendation that greater emphasis be placed upon the benefits of a growth mindset for the student population; an approach equally applicable to academic staff at the university.

\section{Acknowledgements}

Russ Lisk, University of Surrey; Department of Higher Education, University of Surrey. 


\section{References}

Ackermann, E. (2001). Piaget's constructivism, Papert's constructionism: What's the difference? Future of Learning Group Publication. Retrieved from http://www.sylviastipich.com/wp-content/uploads/2015/04/Coursera-Piaget-_Papert.pdf

ASET. (2017). Spring regional hub meetings: Student resilience. Retrieved from http://www.asetonline.org/wp-content/uploads/2017/04/Apr-17.pdf

Caruana, V., Clegg, S., Ploner, J., Stevenson, J., \& Wood, R. (2011). Promoting students' resilient thinking in diverse higher education learning environments. Birmingham: HE Academy Subject Centre for Sociology, Anthropology and Politics.

Cotman, C. W., \& Berchtold, N. C. (2002). Exercise: A behavioral intervention to enhance brain health and plasticity. Trends in Neurosciences, 25(6), 295-301.

Coughlan, S. (2015, September 30). Rising number of stressed students seek help. BBC. Retrieved from http://www.bbc.co.uk/news/education-34354405

Dickinson, M. (2012). STARS: Surrey's top achievers recognised and supported. Retrieved from https://www.surrey.ac.uk/library/documents/learning/STARS\%20pilot\%20FINAL\%2 Oreport.pdf

Dickinson, M. J., \& Dickinson, D. A. G. (2014). Practically perfect in every way: Can reframing perfectionism for high achieving undergraduates impact academic resilience? Studies in Higher Education, 40(10), 1889-1903.

Dweck, C. (2014). The power of believing that you can improve. Retrieved from https://www.ted.com/talks/carol_dweck_the_power_of_believing_that_you_can_impr ove

Dweck, C. (2015). The growth mindset. Retrieved from https://www.mindsetworks.com/science/

Garcia-Dia, M. J., DiNapoli, J. M., Garcia-Ona, L., Jakubowski, R., \& O'flaherty, D. (2013). Concept analysis: Resilience. Archives of Psychiatric Nursing, 27(6), 264270.

Gardner, H. (1993). Frames of mind: The theory of multiple intelligences (2nd ed.). London: Fontana.

Gauntlett, D. (2007). Creative explorations: New approaches to identities and audiences. London: Routledge.

Higher Education Statistics Agency (HESA). (2016). Qualifications obtained. Retrieved from https://www.hesa.ac.uk/data-and-analysis/students/qualifications

Holdsworth, S., Turner, M., \& Scott-Young, C, M. (2017). Not drowning, waving. Resilience and university: A student perspective. Studies in Higher Education. doi: 10.1080/03075079.2017.1284193

Jackson, D., Firtko, A., \& Edenborough, M. (2007). Personal resilience as a strategy for surviving and thriving in the face of workplace adversity: A literature review. Journal of Advanced Nursing, 60, 1-9. doi:10.1111/j.1365-2648.2007.04412.x

James, A. (2013). Lego serious play: A three-dimensional approach to learning development. Journal of Learning Development in Higher Education, 6: 8.

James, A., \& Brookfield, S. D. (2014). Engaging imagination: Helping students become creative and reflective thinkers. San Francisco, CA: Jossey-Bass.

Johnson, B. (2008). Teacher-student relationships which promote resilience at school: A micro-level analysis of student's views. British Journal of Guidance \& Counselling, 36(4), 385-398. doi:10.1080/03069880802364528

Kinchin, I. M. (2015). Pedagogic frailty: An initial consideration of aetiology and prognosis. Paper presented at the annual conference of the Society for Research into Higher Education (SRHE). Celtic Manor, Wales. 
Kinchin, I. M. (2016). The mapping of pedagogic frailty: A concept in which connectedness is everything. In A. Cañas, P. Reiska, \& J. D. Novak (Eds.), Innovating with Concept Maps (pp. 229-240). Switzerland: Springer.

Kinchin, I. M. (2017). Mapping the terrain of pedagogic frailty. In I. M. Kinchin \& N. E. Winstone (Eds.), Pedagogic Frailty and Resilience in the University (pp. 1-16). Rotterdam: Sense Publishers.

Kinchin, I. M., \& Winstone, N. E. (Eds.). (2017). Pedagogic frailty and resilience in the university. Rotterdam: Sense Publishers.

McIntosh, E., \& Shaw, J. (2017). Student resilience: Exploring the positive case for resilience. Retrieved from www.UNITE-Group.co.uk/studentresilience

Novak, J. D. (2010). Learning, creating, and using knowledge: Concept maps as facilitative tools in schools and corporations (2nd ed.). Oxford: Routledge.

Peabody, M. A., \& Noyes, S. (2017). Reflective boot camp: Adapting LEGO® SERIOUS PLAY® in higher education. Reflective Practice: International and multidisciplinary perspectives. 18(2), 232-243. doi:10.1080/14623943.2016.1268117

Ransley, V. (2017). Resilience - An attractive skill for employers and your career. Vicky $\begin{array}{llll}\text { Ransley's Careers } & \text { blog. } & \text { Retrieved }\end{array}$ http://blogs.surrey.ac.uk/careers/2017/08/17/resilience/

Robertson, I., \& Cooper, C. L. (2013). Resilience. Stress and Health, 29(3), 175-176.

Rotter, J. B. (1954). Social learning and clinical psychology (Psychology series). New York, NY: Prentice-Hall.

Schwarzer, R., \& Warner, L. M. (2012). Perceived self-efficacy and its relationship to resilience. In S. Prince-Embury \& D. H. Saklofske (Eds.), Resilience in Children, Adolescents and Adults (pp. 139-150). New York, NY: Springer-Verlag.

Sotto, E. (2007). When teaching becomes learning: A theory and practice of teaching (2nd ed.). London: Continuum.

The Browne Report. (2010). Securing a sustainable future for higher education: An independent review of higher education funding and student finance. Retrieved from https://www.gov.uk/government/publications/the-browne-report-higher-educationfunding-and-student-finance

The Guardian. (2015). How to help a perfectionist student. Retrieved from https://www.theguardian.com/education/2015/may/19/how-to-help-a-perfectioniststudent

The Guardian. (2016). University mental health services face strain as demand rises $50 \%$ Retrieved from https://www.theguardian.com/education/2016/sep/23/universitymental-health-services-face-strain-as-demand-rises-50

The Guardian. (2017). Number of university dropouts due to mental health problems trebles. Retrieved from https://www.theguardian.com/society/2017/may/23/numberuniversity-dropouts-due-to-mental-health-problems-trebles

Turner, M., Holdsworth, S., \& Scott-Young, C, M. (2017). Resilience at university: The development and testing of a new measure. Higher Education Research \& Development, 36(2), 386-400.

Vgontzas, A. N., Zoumakis, M., Bixler, E. O., Lin, H. M., Prolo, P., Vela-Bueno, A., Kales, A., \& Chrousos, G. P. (2003). Impaired nighttime sleep in healthy old versus young adults is associated with elevated plasma interleukin-6 and cortisol levels: Physiologic and therapeutic implications. Journal of Clinical Endocrinology \& Metabolism, 88(5), 2087-2095.

Winstone, N. E. (2017). The '3Rs' of pedagogic frailty: Risk, reward and resilience. In I. M. Kinchin \& N. E. Winstone (Eds.), Pedagogic Frailty and Resilience in the University. Rotterdam: Sense Publishers. 